\title{
Brief Analysis of Characteristics and Further Research Orientation of Bioenergy Supply Chain
}

\section{Mian Lu, Qiuhong Zhao}

School of Economics and Management, Beihang University, Beijing, China.

Email: lumi8an@126.com

Received November $18^{\text {th }}$, 2012; revised December $29^{\text {th }}, 2012$; accepted January $7^{\text {th }}, 2013$

\begin{abstract}
Because of the pressure in environmental protection and the less amount of conventional energy, more and more countries around the world attached great importance to the development and utilization of bioenergy. Using bioenergy effectively and setting up a perfect bioenergy industry chain are the premises for bioenergy to be well developed. The main applications of bioenergy in China are electric power generating and fuel refining. But there is still some gap between China and other countries in bioenergy's development, not only in the technology, but also in government policy support. First of all, this paper briefly introduces the concept and the basic condition, the development and utilization of bioenergy in China. Secondly, this paper makes an analysis and comparison of supply chain for the biomass and coal. Finally, this paper gives some suggestions to the further research orientation of the biomass supply chain based on its characteristics.
\end{abstract}

Keywords: Bioenergy; Supple Chain; Characteristics; Policy Orientation

\section{Introduction}

Bioenergy is a chemical energy that green plants transform from solar energy by photosynthesis and then store inside themselves (This definition is published by China National Committee for Terms in Sciences and Technologies). These energies exist in the form of organic matter. These organic matters provide humans not only food but also various raw materials for production. In some sense, green plants are inexhaustible and kinds of recycled energy as well as only one recycled carbon energy. Biomass includes two major categories and they are planting resources and idle resources.

\subsection{Categories of Biomass}

According to the origin, the biomass can be divided into four major categories. They are forest resources, agricultural resource, urban waste and livestock waste.

1) Forest Resources

Forest biomass resources refer to the energy provided by trees growing and forestry manufacture process.

2) Agricultural Resource

Agricultural biomass resources refer to agricultural crops (including energy crops), the waste of agricultural manufacture process and the waste of agricultural processing industry.

3) Urban Waste
Urban waste includes the waste of living, business, small amount of housing building waste and organic dirty water from living and industry.

4) Livestock Waste

Livestock waste is another form of biomass (like grains, straws, herbage and so on). It is a mixture of feces, urine and straws.

\subsection{Biomass Energy Policies}

Fundamentally, the purpose of the countries all over the world to develop biomass energy is different. Developing countries aim to alleviate the energy shortage problem in the rural and remote areas. However, developed countries have a totally different purpose. The basic motivation is energy shortages and oil crisis.

Firstly, the difference in the research and investment is in consideration. Our government always support of the research and technology development of biomass energy. With the 6th Five-Year Plan beginning, China arranged a certain quantity of capital for the development of bioenergy technology. But compared with the developed countries, the fund of China for biomass energy is much lower. Take the 9th Five-Year Plan for example, The Chinese government arranged less than RMB 100 million for national science and technology research project while the US government's fund for the project was as much as $\$ 1.456$ billion. Secondly, we discuss the differ- 
ence in government subsidy policy. The subsidy policies of other countries are much more than China. Thirdly, the difference on tax cuts. The USA developed bio-energy much earlier. The Energy Revenue Act of 1978 reduced the fuel consumption tax of ethanol gasoline. To support the development of small bioenergy power plants, Finland had made those plants which produced less than 25,000 KWH electricity energy tax-free [1].

\section{Development and Utilization of Bioenergy in China}

China is a large agricultural country. The distribution of major biomass is consistent with crop's distribution. The major biomass-straw mainly distribute in the eastern region including the North China Plain and the Northeast Plain [2,3]. The forest regions of Northeast China and Inner Mongolia, North China, the Central Plains, South China and the tropical regions of South China are the major area of forest biomass resources. Livestock waste mainly concentrates in the developed regions of livestock husbandry. Chinese grazing land mainly locates in North and western border area.

Where there are people, there are house refuse. The types of garbage are different due to the different average life level, energy consumption structure, infrastructure, natural conditions, traditional customs, season variation and so on [4]. In general, the biomass in China is rich and wide spreading which create a good environment for the bioenergy industry development.

In developed countries, biomass power generation has been very mature. It has become an important way to produce power and heating. Nowadays, the capacity of the biomass power is more than total capacity of wind energy, solar and geothermal energy in American and this trend is expected to continue [5]. Due to the active participating of the government, enterprises, scientific research departments, the proportion of bioenenrgy in total energy consumption has been close to $4 \%$.

Compared with foreign countries, the development of bioenenrgy in China is late. Although there is certain gap, we have our own advantages. In recent years, China's bioenergy industry is booming. Combined with China's national conditions, the resources and regional characteristics, the main bioenergy project of China is biomass gasification combined cycle power generation technology and technology for liquid fuel refined by Biomass. The mature biomass power generation enterprises in China at present are Nation Bioenergy Group, Wuhan Kaidi Electric Power Co., Ltd. and so on. In recent years, China has issued a series of policies to foster the development of biomass power plant. In July 2010, China carried out the unified electrovalence policy $(0.75$ yuan/KWH). This policy is a great support to biomass power plant and re- verses the defective situation. The mature biomass liquid fuel production enterprises in China at present are ANHUI BBCA BIOCHEMICAL CO., LTD, COFCO and so on. So far, these enterprises can't operate only depend on market. If there are no subsidies, these enterprises would face huge losses. Therefore, the government plays an irreplaceable role in the development of bioenergy industry. What's more, the setting and optimization of the supply chain is also a key factor to bioenergy industry.

\subsection{Problems Faced by Bioenergy Enterprises}

As the development and utilization of bioenergy get the attention of the society in China only for few years, the development of bioenergy industry still has big problems and difficulties. For the moment, the high cost of collection, storage, transportation of biomass is one of the barriers to widely use of bioenergy. What's worse, many advanced equipments have to rely on foreign imports which makes more costly. In some region with abundant biomass resources, two or more enterprises struggle to collect biomass but there is no enough resources meet the needs of all enterprises. Therefore, some enterprises will have to be in the state of shutdown. This is the irrationality of planning and layout. At present, the main challenges to domestic bioenergy enterprise are the innovation of technology, the perfection of biomass supply chain and business model innovation. Doing well in these three aspects is a key to success.

\subsection{The Significance of Bioenergy Supply Chain Research}

The biomass energy sources have many advantages such as they are renewable, environmental friendly, rich varieties, helpful to solve "Three Dimensional Rural Issues" and so on, so widely use of bioenergy will be an inevitable trend. However, there are apparent obstacles in the development of bioenergy. One of them is supply. Take the straw power generation for example: one typical 30 mw power plant consumes about 250,000 to 300,000 tons of straw every year. The total annual cost of the biomass is about 70 million yuan to 90 million yuan. If the straw is unable to supply in time, the power plant will come to a shutdown. On the contrary, if the Biomass power plant has enough production, due to the high cost, no one wants to buy his production and it will have a negative effect on bioenergy industry. The above problems show the two major problems in management of supply chain: the stability and cost of the supply chain. It is extremely important to the future of the bioenergy industry to build a stable, low cost and high efficiency supply chain. 


\section{Analysis of the Characteristics of Biomass Supply Chain}

\subsection{Characteristics of Bioenergy}

1) Renewable

Bioenergy is recycled as wind and sun energy and can reproduce by photosynthesis of green plants. It is inexhaustible.

2) Environment-friendly

The content of sulphur and nitrogen in biomass is low. The combustion process of biomass produces less pollution. Biomass fuel can effectively reduce the greenhouse effect.

3) Widely distributed

Almost every area in China has many types of crops can be used as bioenergy, so the area lacking of coal can make full use of biomass.

4) Abundant Supply

Each year about 400 million tons of straw can be used as energy in China. What's more, there are also many other kind of biomass. If these resources can be fully used, the total energy will be amazing.

5) Low Density

Most kinds of the biomass are low density of distribution, which put forward a higher request to the supply chain of biomass.

6) Difficult to collect

Due to the small scale of the farming, low degree of mechanization, backward facilities, it is difficult to collect, store and transport the biomass [6].

7) Periodism

The use of bioenergy is cyclicality because Crops and forestry biomass have obvious seasonality [7].

\subsection{The Difference between Bioenergy Supply Chain and Coal Supply Chain}

The biomass supply chain management is very important to bioenergy enterprises. According to the characteristics of the bioenergy, we compare the biomass supply chain with coal supply chain, and then do some analysis. Figure $\mathbf{1}$ shows the structure of biomass supply chain. Figure 2 shows the structure of coal supply chain.

The main participants in the bioenergy supply chain are farmers, bioenergy enterprises and bioenergy consumers. The main links of bioenergy supply chain are biomass's farming, harvest, processing, storage, filed transport, loading, road transport, unloading, storage, manufacture and sale. Among them, farmers mainly participate in farming, harvest, processing, storage, filed transport. The enterprises mainly involve in loading, road transport, unload, storage, manufacture and sale [8].

Nonetheless, in the current environment, the government plays an important role in the bioenergy supply chain to guide, coordinate, stable and support. The main function of government is to make the suitable policies to guide farmers to plant biomass materials more positive and encourage enterprises to produce more by economic and political policy.

Coal production enterprise is the core of coal supply chain. Its upstream enterprise is the material and equipment suppliers and its downstream enterprises are coal operators and users $[9,10]$. The main links of coal supply chain are preparation for mining, coal mining, processing, storage, transport, unloading, sale, the use of coal production.

With comparison between biomass supply chain and coal supply chain, we come to some conclusions:

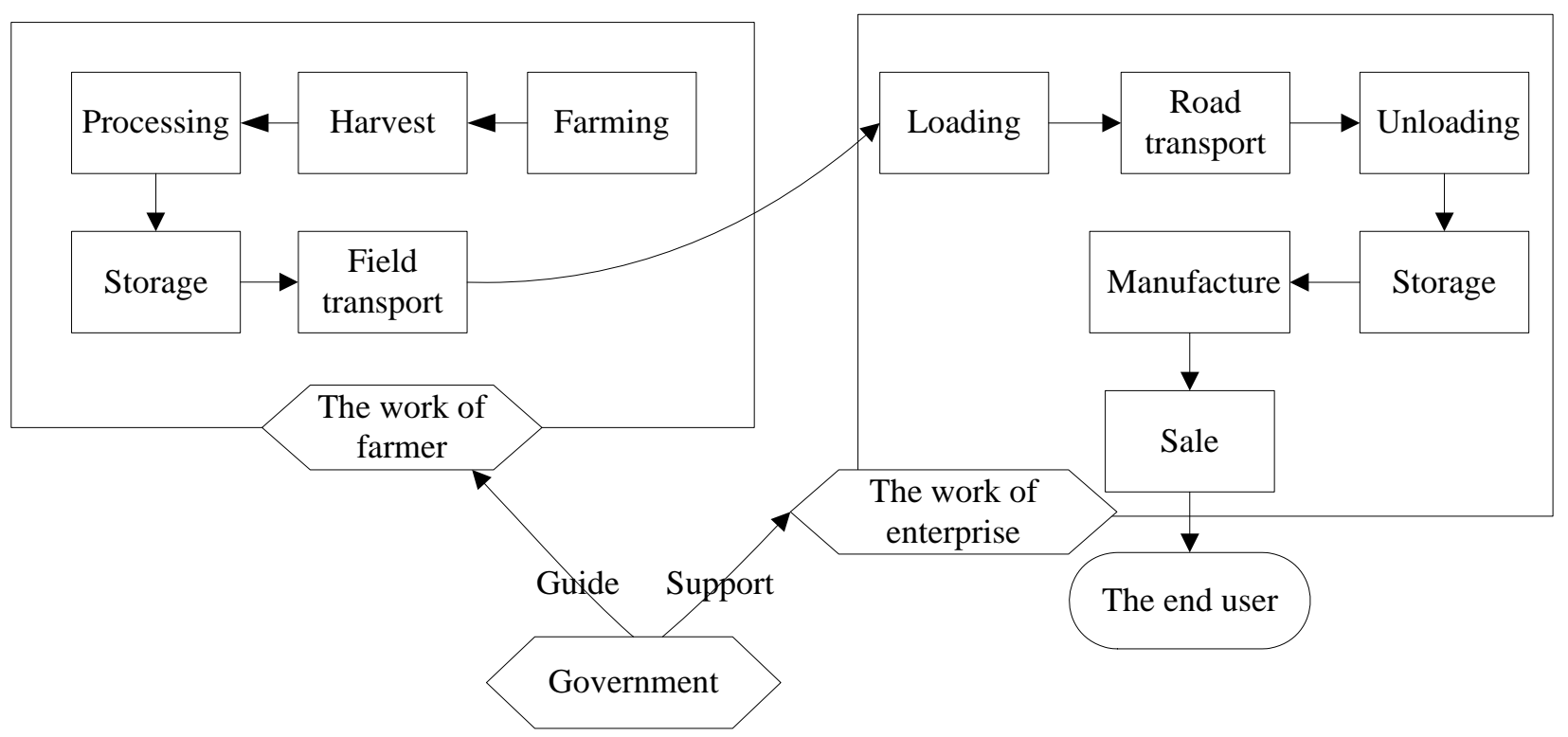

Figure 1. The structure of biomass supply chain. 


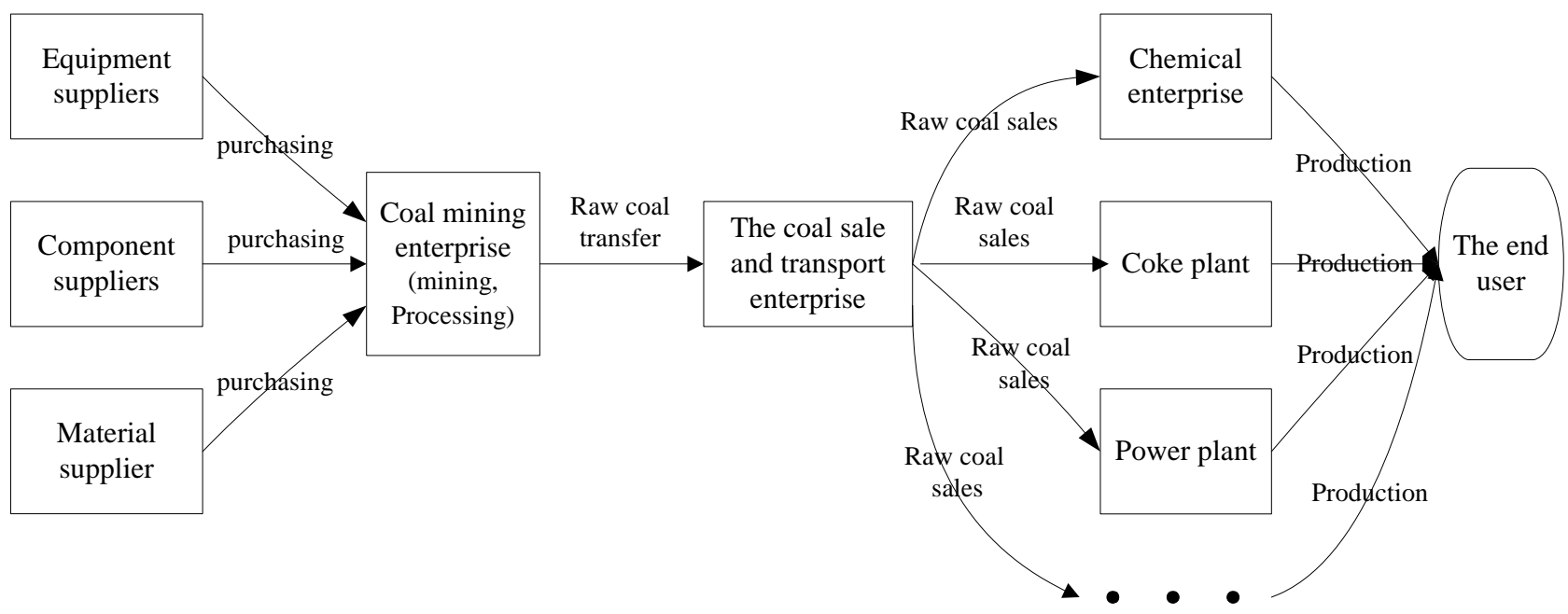

Figure 2. The structure of coal supply chain.

1) Coal supply chain has less links and shorter in the structure; 2) The governments do more works in the biomass supply chain; 3 ) Nowadays, the most raw coal suppliers are big companies and it is easier for them to purchase the raw materials. However, biomass usually comes from individual farmers. It is more difficult to collect. Therefore, the efficiency of biomass supply chain is greatly reduced; 4) The biomass is greatly influenced by season, but it has no influence on coal, so the coals supply chain relatively stable; 5) The biomass has characteristics of big volume, low density and wide distribution so that the efficiency of transportation is greatly reduced; 6 ) The transmission of coal will produce the dust pollution, but the biomass supply chain almost makes no pollution.

\section{Development of the Biomass Supply Chain in the Future}

\subsection{Suggestions}

According to the characteristics of biomass supply chain, we make some advices to the use of bioenergy.

1) Due to the characteristics of the biomass, bioenergy enterprise should be set up near the sources of raw materials in order to reduce the transportation cost.

2) In order to avoid the competition of raw material collection, it is better to set up only one bioenergy enterprise in a certain area. If two or more enterprises use different kinds of raw materials, they can develop together in a certain range.

3) With the characteristics of farming in China, the bioenergy enterprise should set up some collecting stations where it is appropriate. At the same time, the bioenergy enterprise should encourage farmers to sell their biomass and sign a contract with farmers who grow biomass in large scale. These methods can ensure the stability and succession of the biomass supply chain.
4) The local government should make suitable policies according to local condition to coordinate the local biomass supply chain. It is necessary for the government to draw up a blueprint for the development of bioenergy industry in the future [11,12].

\subsection{The Further Research Orientation of Research}

In the future, the cost, efficiency, stability and continuity of the biomass supply chain will be the key factors in the study of the biomass supply chain. Here are the key aspects as below.

1) The location of the enterprise.

2) The route design and cost of the biomass transporttation.

3) The selection of the tools and modes for transportation.

4) The selection of purchasing modes of biomass.

5) Coordination of all parts in the biomass supply chain.

6) The government guiding effects on the biomass supply chain.

7) Design and simulation for logistics system of biomass.

\section{Acknowledgements}

The work of this study is supported by National Natural Science Foundation of China under Project Nos. 71071007 and 70821061.

\section{REFERENCES}

[1] Q. Zhang, et al., "Research on the Bioenergy Policy at Home and Abroad," China New Energy Chamber of Commerce, 2011.

http://www.cnecc.org.cn/dispArticle.asp?id=10212 
[2] J. C. Jiang and H. Ying, "The Trend of Energy Conversion Technology of Forestry Biomass in China," Chemistry and Industry of Forest Products, Vol. 25, 2005, pp. 10-14.

[3] H. P. Zhong, Y. Z. Yue and J. W. Fan, “Characteristics of Crop Straw Resources in China and Its Utilization,” Resources Science, Vol. 25, No. 4, 2003, pp. 62-67.

[4] Z. Jun and S. Y. Wang, "Research of Distribution and Application Potential of Agricultural Biomass and Forest Biomass in China,” Journal of Agricultural Mechanization Research, Vol. 6, 2008, pp. 231-233.

[5] Y. Deng, et al., "Plans and Actions on Biomass Research in the USA,” China Biotechnology, Vol. 30, No. 1, 2010, pp. 111-116.

[6] A. A. Rentizelas, A. J. Tolis and I. P. Tatsiopoulos, "Logistics Issues of Biomass: The Storage Problem and the Multi-Biomass Supply Chain,” Renewable and Sustainable Energy Reviews, Vol. 13, No. 4, 2009, pp. 887-894. doi:10.1016/j.rser.2008.01.003

[7] L. T. Richard, "Challenges in Scaling up Biofuels Infra- structure,” Science, Vol. 329, No. 5993, 2010, pp. 793796. doi:10.1126/science.1189139

[8] Y. Zhang, X. J. Chen and Y. M. Jing, "Study on Supply Chain Coordination System of Biomass Energy,” Logistics Technology, Vol. 28, No. 3, 2009, pp. 119-122.

[9] L. Q. Su and B. D. Yu, "The Construction of Coal Supply Chain,” China Coal, Vol. 32, No. 5, 2006, pp. 19-21.

[10] Y. M. Wang and X. S. Wang, "Research on the Management of Coal Supply Chain,” China Coal, Vol. 33, No. 9, 2007, pp. 22-23.

[11] Z. H. Fu, X. Y. Wang and G. J. Wang, "The Support Policy System of Development of Rural Bioenergy Industry," Review of Economic Research, Vol. 7, No. 2135, 2008, pp. 9-24.

[12] H. Ye, "SWOT Analysis on Sustainable Development of Bioenergy Industry and Countermeasure in China," Journal of Southwests Forestry College, Vol. 28, No. 4, 2008, pp. 12-15. 